\title{
Effect of Laser Welding Process Parameters and Filler Metals on the Weldability and the Mechanical Properties of AA7020 Aluminium Alloy
}

\author{
Saheed B. Adisa ${ }^{1, *(\mathbb{D})}$, Irina Loginova ${ }^{2}$, Asmaa Khalil ${ }^{2}$ (1) and Alexey Solonin ${ }^{2}$ (D) \\ 1 Department of Chemical and Materials Engineering, University of Idaho, Moscow, ID 83844, USA \\ 2 Department of Physical Metallurgy of Non-Ferrous Metals, National University of Science and \\ Technology (MISIS), Moscow 119049, Russia; i-popkova@list.ru (I.L.); \\ eng.asmaa.m.khlil@outlook.com (A.K.); solonin@misis.ru (A.S.) \\ * Correspondence: adis8947@vandals.uidaho.edu; Tel.: +1-208-5965-232
}

Received: 7 April 2018; Accepted: 29 May 2018; Published: 1 June 2018

\begin{abstract}
This research work aims at finding the optimum process parameters for the laser welding of AA7020 aluminium alloys. The use of 7xxx series alloys is limited because of weldability problems, such as hot cracking, porosity, and softening of the fusion zone despite its higher specific strength-to-weight ratio. AA7020 aluminium alloy was welded while varying the process parameters so as to obtain optimal welding efficiency. The welded samples were analysed to reveal the microstructure, defects, and mechanical properties of the welded zone. The samples were prepared from a plate of AA7020, which was hot rolled at a temperature of $470{ }^{\circ} \mathrm{C}$ to a thickness of $1 \mathrm{~mm}$. The welding was carried out at an overlap of $0.25 \mathrm{~mm}$, duration of $14 \mathrm{~ms}$ and argon shield gas flow rate of $15 \mathrm{~L} / \mathrm{min}$. Process parameters, such as peak power, welding speed, and pulse shaping, were varied. The samples were welded with Al-5Ti-B and Al-5Mg as filler metals. The welding speed, peak power, and pulse shaping have a great influence on the weldability and hot cracking susceptibility of the aluminium alloy. Al-5Ti-B improves the microstructure and ultimate tensile strength of AA7020 aluminium alloy.
\end{abstract}

Keywords: laser beam welding; Aluminium alloys; filler materials; mechanical properties; process parameters

\section{Introduction}

As environmental awareness grows among consumers as well as government agencies, attempts to improve fuel economy in automobiles are accelerating [1,2]. In addition to improved powertrain efficiency, vehicle weight reduction is an important factor. The ability of a steel body structure to deliver weight savings is limited, so the use of aluminium in auto body structures is increasing, and is projected to expand further in the next decade [3]. Owing to their low density and good mechanical properties, aluminium alloys are increasingly being employed in many important manufacturing areas, such as the automobile industries, aeronautics and the military [4-6]. Friction-stir welding (FSW) and laser beam welding (LBW) are noteworthy for their present use in commercial aircraft manufacturing [7-11]. LBW has accounted for a 5\% reduction in the weight of Airbus A300 series structures and has also been employed to join some parts of the fuselage [4]. LBW was used to join critical parts in the fuselage in order to mitigate possible materials problems.

Hybrid laser arc welding is also a promising technology that has been used to achieve high performance and low welding deformation. In addition, this technology has the possibility of varying the chemical composition and mechanical properties of welds due to the melting of the electrode. 
It takes advantage of the positive properties of both laser and arc welding and produces a synergistic effect. The use of this process is fairly limited when compared with laser welding because of the large amount of process parameters involved which must be adjusted simultaneously and must be chosen carefully in order to achieve an effective process [12]. Thermal field modelling by E. Ukar et al. has helped to reduce surface roughness and identify the optimum process parameters with minimum experimentation in laser processing of 1.234 tool steel [13]. An algorithm solution for feed variation control together with optimum laser power has been applied to obtain more homogenous structure in laser applications $[14,15]$.

Medium-strength aluminium alloys such as 5xxx (Al-Mg) and 6xxx (Al-Mg-Si) series alloys are already widely used due to their high strength-to-weight ratio, good formability, weldability, and corrosion resistance. The use of $7 \mathrm{xxx}(\mathrm{Al}-\mathrm{Zn})$ series alloys is limited when compared to $5 \mathrm{xxx}$ and 6xxx despite its higher strength-to-weight ratio, because of weldability problems such as hot cracking, porosity, and softening of the fusion zone [16]. AA7020 (Al-Zn-Mg) has moderate strength and is widely used in welded joints of armoured vehicles, cryogenic pressure vessels, components of spacecraft liquid-propellant engines, and bridge beams for roads and railroad systems [17].

Process parameters such as laser power, welding speed, defocusing distance, feed rate and pulse shaping have a strong influence on the mechanical properties, weld penetration and bead quality; high speed may result in incomplete fusion, porosity, or high spattering, and high laser power can lead to collapse and instability of the weld pool. Selecting appropriate process parameters is difficult, which necessitates the need to build a relationship between the processing parameters and the quality of weld joint [18].

In this research, 1.0-mm-thick samples of AA7020 were butt welded with filler metals using a Nd:YAG laser. Laser power, welding speed, and pulse shaping were varied as well as the filler metal used to evaluate their effect on the microstructure and mechanical properties of the welded sample.

\section{Experimental Work}

The chemical composition of the AA7020 alloy used is given in Table 1.

Table 1. Composition of AA7020.

\begin{tabular}{cccccccccc}
\hline \multicolumn{10}{c}{ Element, wt.\% } \\
\hline $\mathrm{Al}$ & $\mathrm{Zn}$ & $\mathrm{Mg}$ & $\mathrm{Mn}$ & $\mathrm{Cu}$ & $\mathrm{Cr}$ & $\mathrm{Fe}$ & $\mathrm{Si}$ & $\mathrm{Ti}$ & $\mathrm{Zr}$ \\
Balance & 5 & 1.2 & 0.5 & 0.3 & 0.2 & 0.3 & 0.3 & 0.05 & 0.2 \\
\hline
\end{tabular}

The filler metals used were Al-5Ti-B and Al-5Mg. Samples were cut from a sheet of AA7020, which was prepared by hot rolling at $470{ }^{\circ} \mathrm{C}$ to a thickness of $300 \mathrm{~mm}$ and subsequent cold rolling down to $1 \mathrm{~mm}$ in a laboratory rolling mill.

Before welding, the surface of each sample was cleaned using acetone and dried to remove any oxide layer and contamination present. After the oxide layer has been removed, the surfaces to be welded were electropolished using a $\mathrm{C}_{2} \mathrm{H}_{5} \mathrm{OH}+\mathrm{HClO}_{4}$ electrolyte under $20 \mathrm{~V}$ and then dried in a furnace at $150{ }^{\circ} \mathrm{C}$ for $10 \mathrm{~min}$.

The welding process was carried out using a MUL-1-M200 pulse-periodic laser welding machine equipped with a Nd:YAG laser operating at a wavelength of $1064 \mathrm{~nm}$, defocus amount of $-2 \mathrm{~mm}$, and a pulse duration of $8 \mathrm{~ms}$. A shield gas flow of high-purity argon was applied during welding from the top, rear, and lateral sides of the sample at a flow rate of $15 \mathrm{~L} / \mathrm{min}$. Metallographic samples of the weld seam were prepared using standard mechanical polishing procedures and etched in a saturated solution of $\mathrm{H}_{3} \mathrm{BO}_{3}$ and $\mathrm{HF}$ in distilled water at $17 \mathrm{~V}$. The microstructure of the weld seam was characterized using a TESCAN VEGA 3LMH scanning electron microscope (SEM).

The effects of varying the welding speed from 0.25 to $7 \mathrm{~mm} / \mathrm{s}$, peak power from 0.81 to $0.97 \mathrm{~kW}$, and square and ramp-down pulse shaping were evaluated. 
The micro-hardness of the etched samples was tested with a Wolpert Wilson HVD-1000AP micro Vickers hardness testing machine with a hardness scale of HV 0.2, at duration of $5 \mathrm{~s}, 1960 \mathrm{~N}$ testing force, with a square-based pyramid indenter with an apical angle of $136^{\circ}$. Tensile testing was performed using an all-around series Zwick/Roell Z250 testing machine. The strain rate was $4 \mathrm{~mm}$ per minute and the standard deviation from the mean value was within $\pm(2-4) \mathrm{MPa}$ of the measured value.

The experiment was designed to study the influence of each parameter on the weld quality when other parameters were kept constant. With these experiments, optimized parameters for high-quality full penetration and high-strength welded joint can be determined.

\section{Results and Discussion}

\subsection{Effect of Peak Power}

Experimental observation of the weld showed that both the width and depth of the weld area increases with increasing peak power, as can be seen in Figure 1. This change with peak power is more clearly visible in the graph shown in Figure 2. A higher peak power raises the input energy delivered on the weld seam, thus resulting in a comparatively large amount of vaporized or melted metal. By careful observation of the weld seam cross-section, it is clear that near full penetration occurred within the laser peak power range of $0.91-0.97 \mathrm{~kW}$ at a welding speed of $2 \mathrm{~mm} / \mathrm{s}$; sputtering was observed at a laser peak of $0.97 \mathrm{~kW}$.
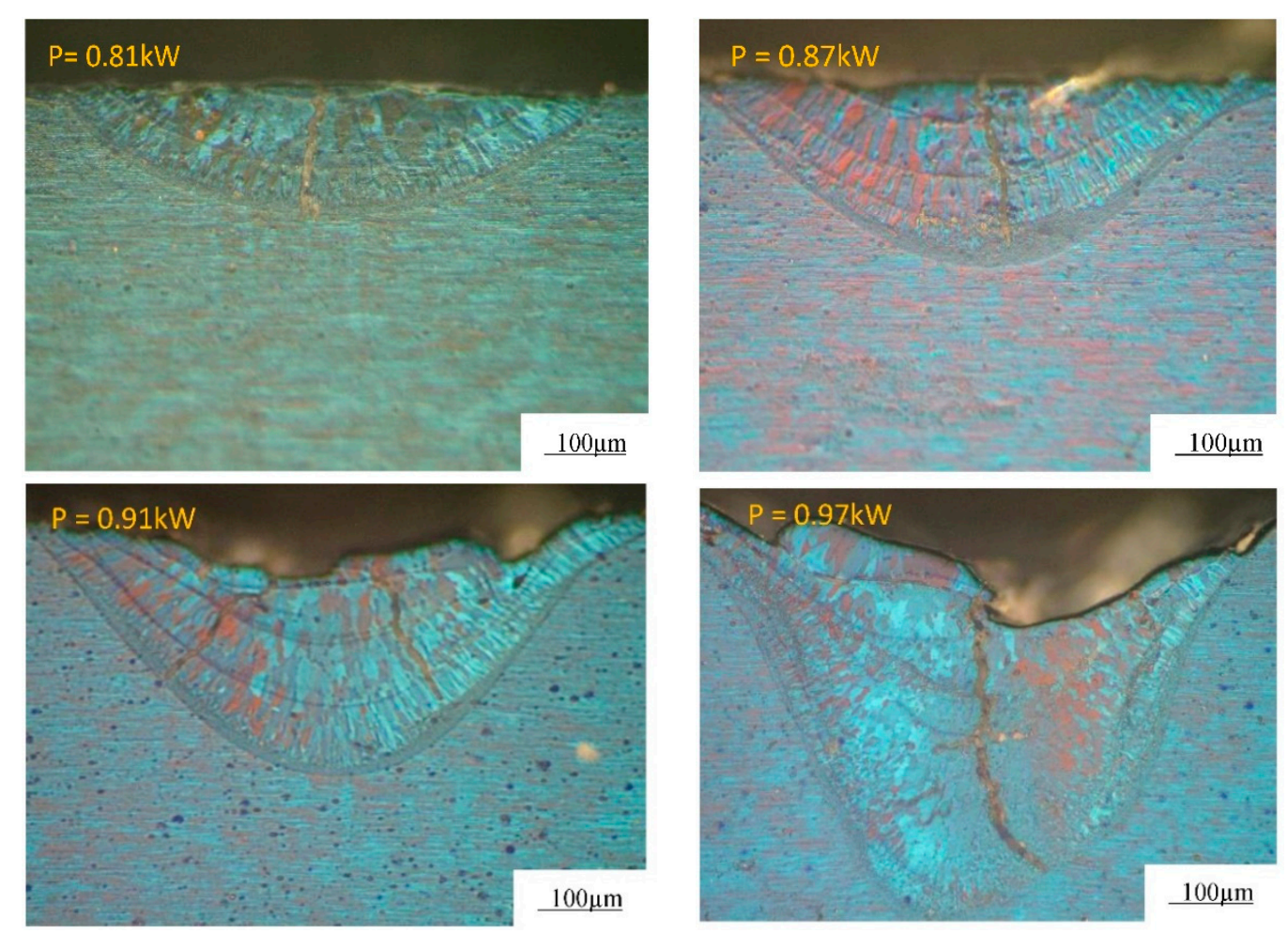

Figure 1. Influence of laser peak power on the cross-section shape of the weld seam. (V=2 mm/s; $\left.\mathrm{Ar}_{\mathrm{f}}=15 \mathrm{~mm}^{-1} ; \Delta \mathrm{z}=-2 \mathrm{~mm}\right)$. 


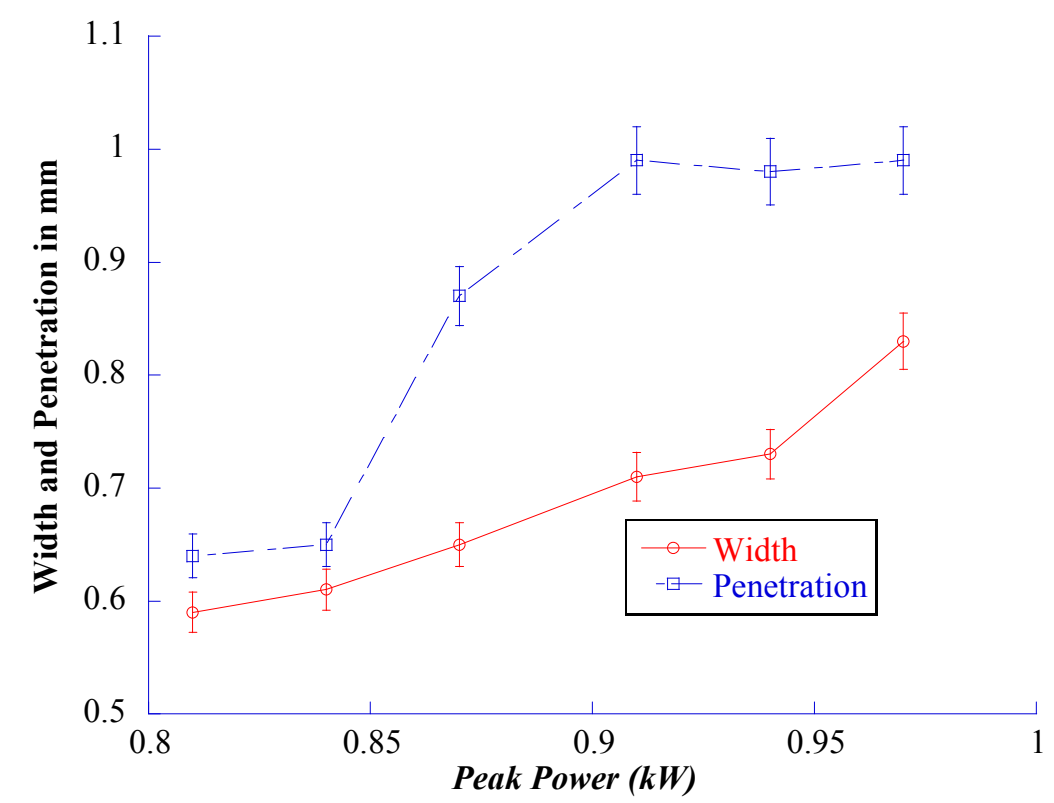

Figure 2. Influence of laser peak power on the weld width and penetration.

\subsection{Effect of Laser Speed}

Figure 3 shows how the shape of the weld changes as the laser speed increases. It was observed that the welding depth and width decrease with increasing laser speed, as clearly represented in Figure 4 . This is because the speed acts in the opposite manner to the input heat, i.e., welding speed is inversely proportional to the input energy per unit weld length delivered on the weld line, reducing the intermixing of the melt. In this case, the depth became shallow and the width became narrower. Spatter occurs at a laser speed of $7 \mathrm{~mm} / \mathrm{s}$.
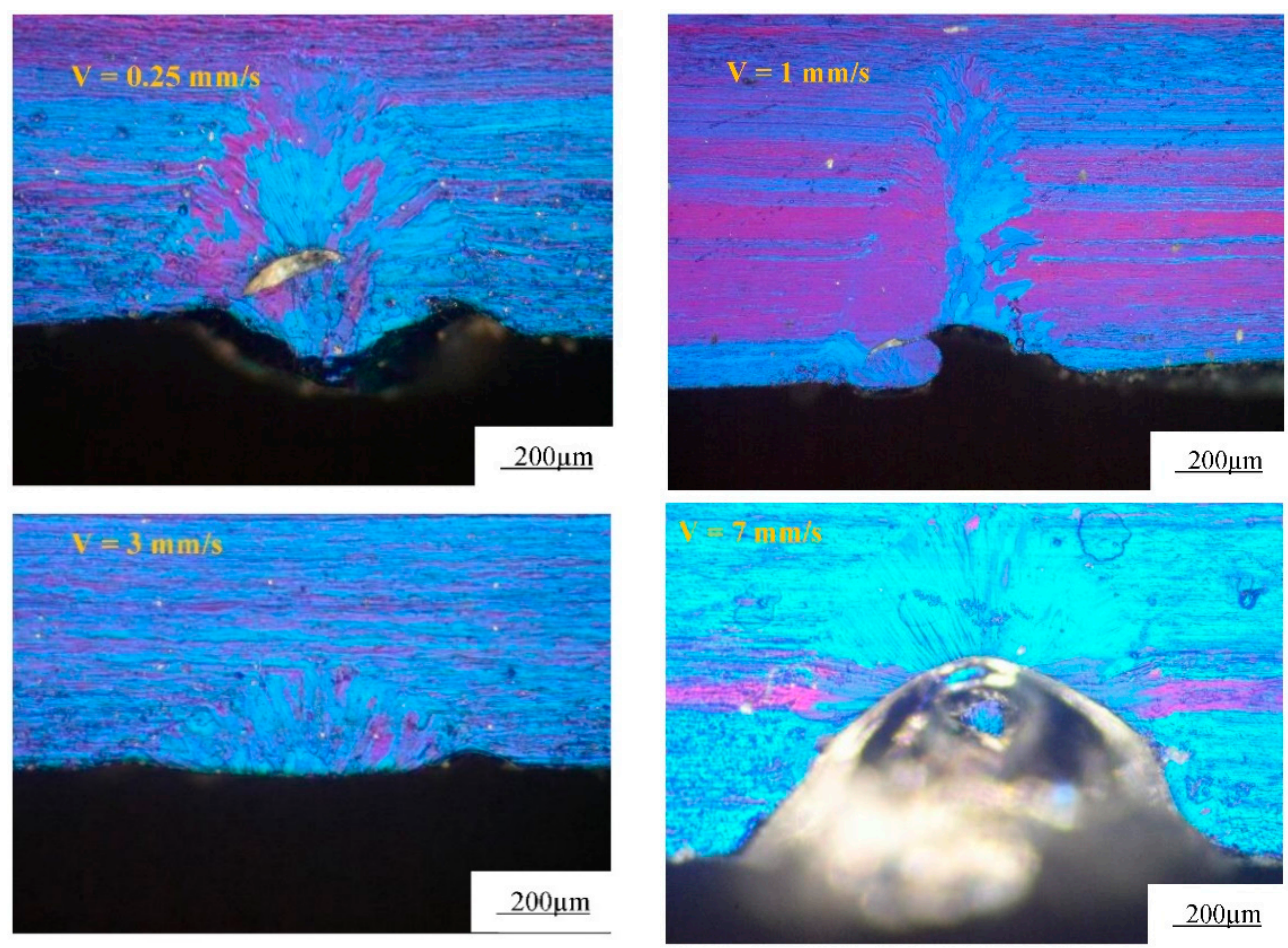

Figure 3. Influence of laser speed on the cross-section morphology of the weld seam. $(\mathrm{P}=0.91 \mathrm{~kW}$; $\left.\mathrm{Ar}_{\mathrm{f}}=15 \mathrm{~mm}^{-1} ; \Delta \mathrm{z}=-2 \mathrm{~mm}\right)$. 


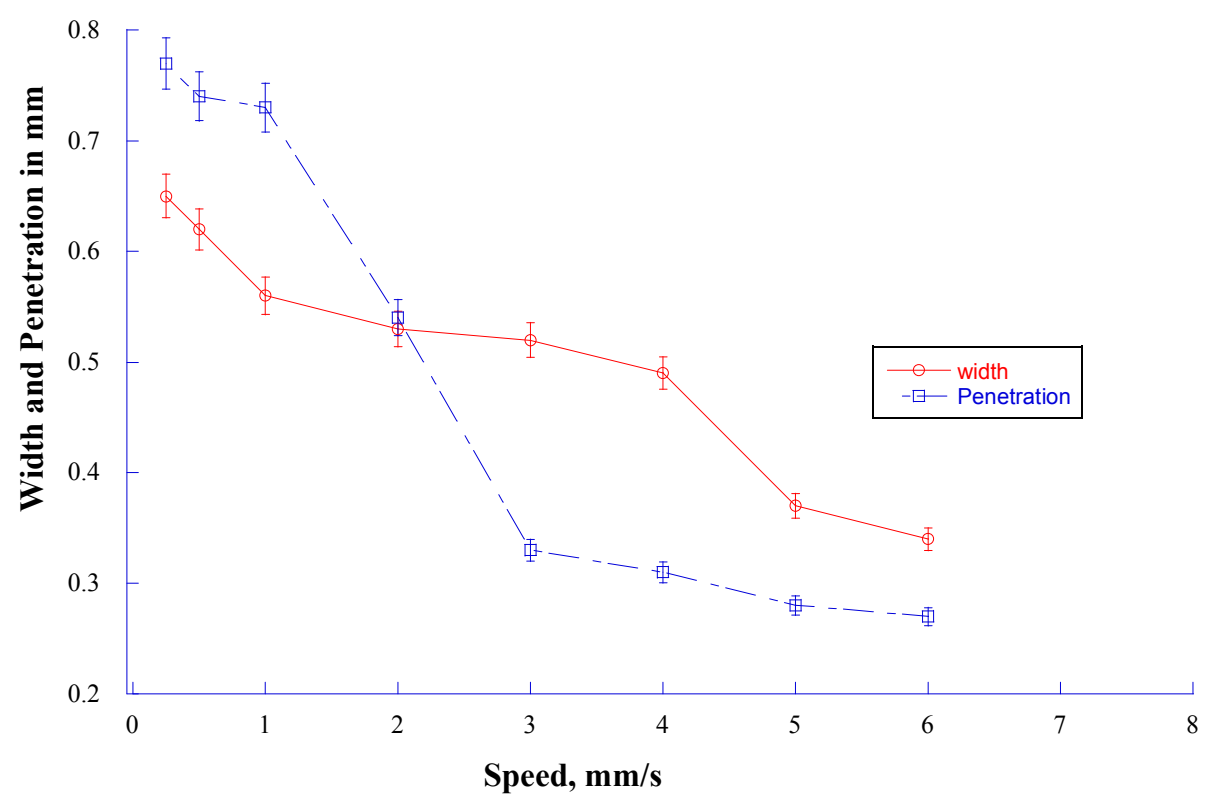

Figure 4. Influence of laser speed on the weld width and penetration.

\subsection{Effect of Laser Pulse Shaping}

Since the reflectance of the laser beam on aluminium alloys is high, there is insufficient absorption of the laser beam to melt the surface unless the laser power is high enough. The barriers to reaching the melting point of the alloy are low laser beam absorption at room temperature and latent heat of fusion at the melting point. A higher peak pulse power compensates for the reflectivity of the aluminium surface, which results in reaching the desired surface temperature.

The influence of square and ramp-down pulse shaping on laser spot welding were investigated at the optimised peak power and speed. Figure 5 a shows a designed square pulse shape consisting of 8 sectors with constant peak power and pulse duration. Figure $5 b$ shows a designed ramp-down pulse shaping consisting of 8 sectors with constant pulse duration, where the peak power is initially at a level high enough to induce melting of the metal surface and subsequently decreases for the remaining pulses. Experimental observation of the spot weld shown in Figure 6a reveals that square pulse shaping induces hot cracking on the weld due to the rapid and uncontrolled cooling rate. No hot cracking was observed on the spot with ramp-down pulse shaping (Figure 6b), because the reduced power level at the end of the pulse sequence provided for a more gradual and controlled cooling rate.

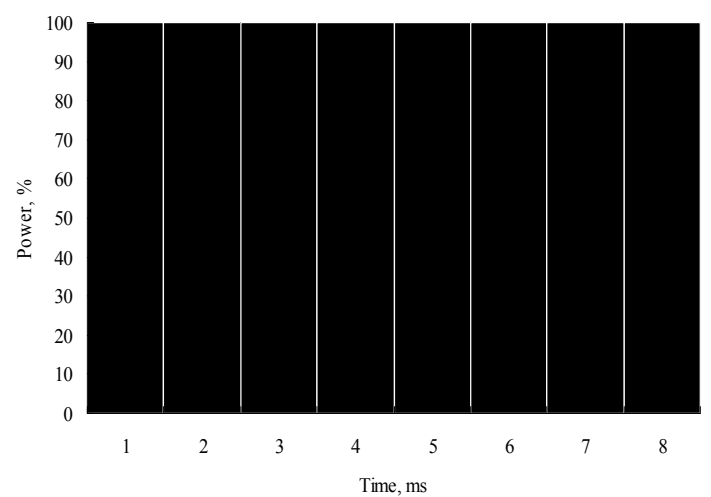

(a)

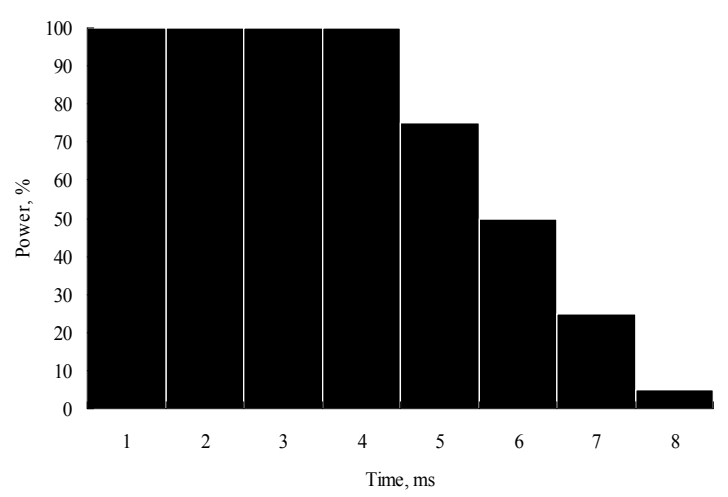

(b)

Figure 5. Laser pulse shaping: (a) square pulse shaping; and (b) ramp-down pulse shaping. 


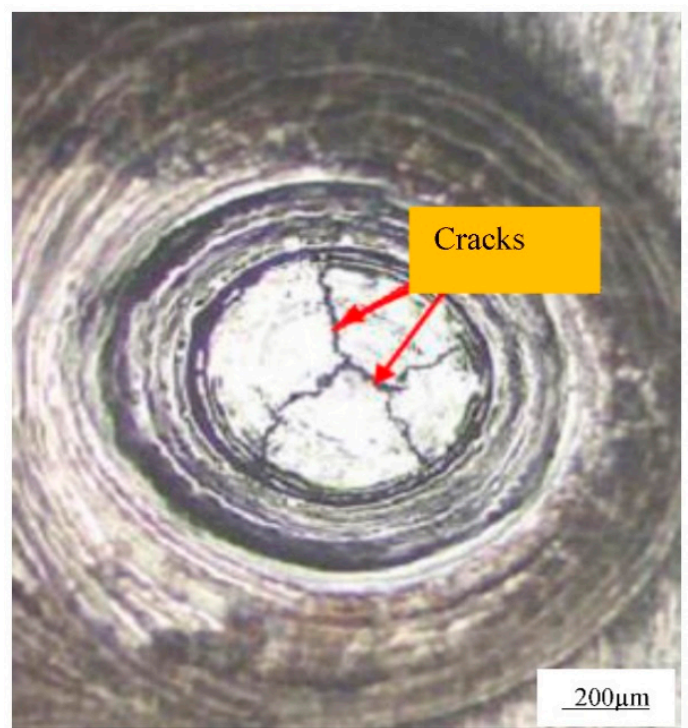

(a)

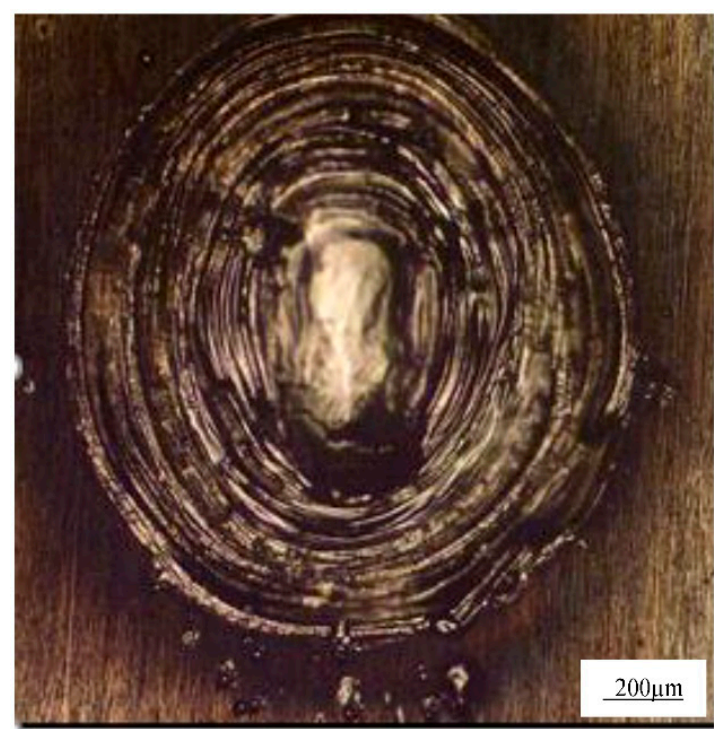

(b)

Figure 6. Influence of pulse shaping on laser spot weld: (a) square; and (b) ramped down.

\subsection{Influence of Filler Metal on the Microstructure and Mechanical Properties}

Generally, laser beam welding requires there to be no gap between the workpieces. However, using a filler metal increases the weld gap bridging ability, thus reducing the amount of work required to prepare the seam and can also be used to alter the properties of the metal in specific ways. Al- $5 \mathrm{Mg}$ and Al-5Ti-B were the two filler metals used. Al-5Mg is the most used filler metal for welding 6xxx series aluminium alloys. $\mathrm{Al}-5 \mathrm{Ti}-\mathrm{B}$ is known to be an excellent grain refiner [19]. $\mathrm{Al}_{3} \mathrm{Ti}$ is the primary phase formed during solidification and $\mathrm{TiB}_{2}$ phase provides grain refinement. These phases have similar lattice parameters $\left(\mathrm{a}=0.5446 \mathrm{~nm}\right.$ and $\mathrm{a}=0.3029 \mathrm{~nm}$ for $\mathrm{Al}_{3} \mathrm{Ti}$ and $\mathrm{TiB}_{2}$, respectively $)$ as compared with $\mathrm{Al}(\mathrm{a}=0.4049 \mathrm{~nm})$. The filler materials were $0.25 \mathrm{~mm}$ thick and were placed between the base alloys. The microstructures of the welded joints are presented in Figure 7. It was observed that the joint with Al-5Ti-B has little or no porosity or hot cracking and has a fine equiaxed grain with an average size of $2.00 \pm 0.26 \mu \mathrm{m}$. The grains in the joint welded with Al-5Mg filler are columnar and porosity appears as a defect which might be associated with the high level of magnesium in the weld zone.

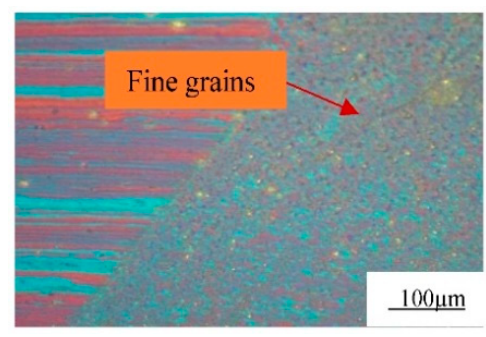

(a)

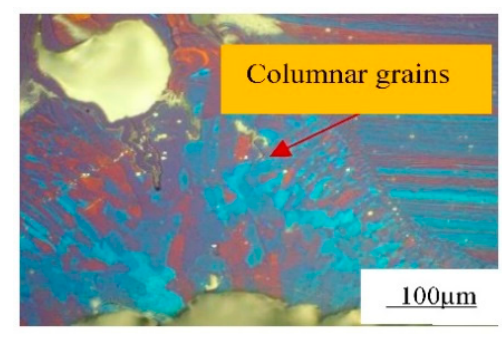

(b)

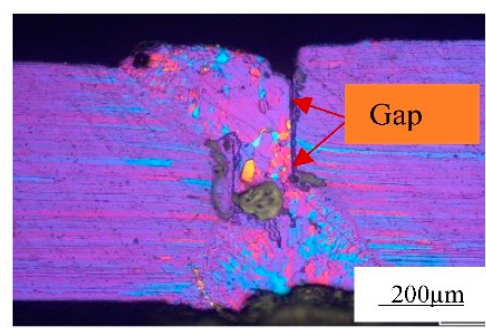

(c)

Figure 7. Microstructure of the welded joints: (a) with Al-5Ti-B; (b) with Al-5Mg; and (c) without filler metal.

Figure 8 shows the elemental distribution in the base metal and the weld zone. Alloying elements are found depleted in the fusion zone because of the large amount of energy accumulated during welding. The levels of $\mathrm{Zn}$ and $\mathrm{Mg}$ present in the weld are lower in the fusion zone and higher near the heat affected zone due to their low boiling point. Ti concentration is highest in the fusion zone when 
compared to other alloying element because of the added Al-5Ti-B to the molten pool. Ti and Zr play a vital role in refining the grains. Mn concentration is lower in the fusion zone, but the little that is present forms dispersed second phases of $\mathrm{MnAl}_{6}$ and $(\mathrm{Cr}, \mathrm{Mn}) \mathrm{Al}_{12}$, which is effective in suppressing grain growth [20].

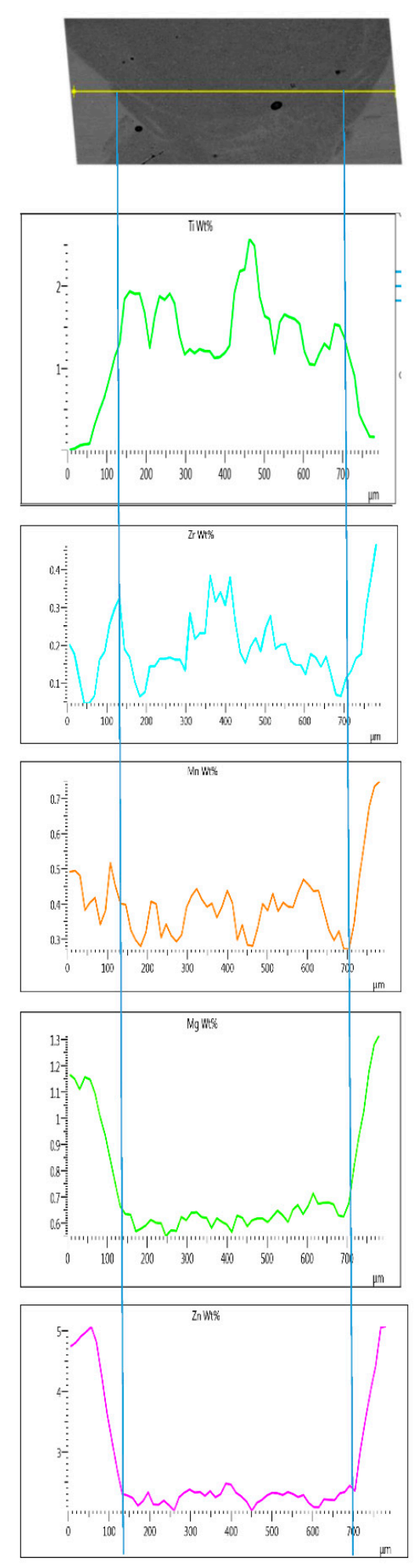

Figure 8. Elemental distribution in the base metal and weld zone of AA7020 after welding with AlTiB filler metal. 
The microhardness profile of the welded joint is presented in Figure 9. The hardness profile shows that the welded joint is mechanically and compositionally heterogeneous, which makes the fusion zone the weakest part of the welded structure. It can be seen that the hardness decreases gradually from a maximum value in the zone of the base metal to a minimum value in the weld zone. The lower hardness in the weld zone was due to the evaporation of strengthening elements, thereby preventing the formation of strengthening precipitates [21]. However, the refinement of grains in the weld zone with Al-5Ti-B explains the higher hardness in the joint relative to the joint with Al-5Mg. The mean hardness in the weld zone with Al-5Ti-B and Al-5Mg filler metal is $102 \mathrm{HV}$ and $88 \mathrm{HV}$, respectively. Table 2 presents the result of the tensile tests of the specimens. The welded joint with Al-5Ti-B has a yield strength and ultimate tensile strength of $88 \%$ and $97 \%$ of the value of the base metal respectively, and the welded joint with Al-5Mg filler metal has yield strength and ultimate tensile strength of $68 \%$ and $67 \%$ of the base metal, respectively.

Table 2. Mechanical properties of the welded joint of AA7020.

\begin{tabular}{cccc}
\hline & $\boldsymbol{\sigma}_{\mathbf{0 . 2}}, \mathbf{M P a}$ & $\boldsymbol{\sigma}_{\mathbf{y}}, \mathbf{M P a}$ & $\boldsymbol{\delta}, \boldsymbol{\%}$ \\
\hline Base Metal & 310 & 372 & 14.0 \\
With Al-5Ti-B & $273(88 \%)$ & $360(97 \%)$ & 8.0 \\
With Al-5Mg & $210(68 \%)$ & $250(67 \%)$ & 4.2 \\
\hline
\end{tabular}

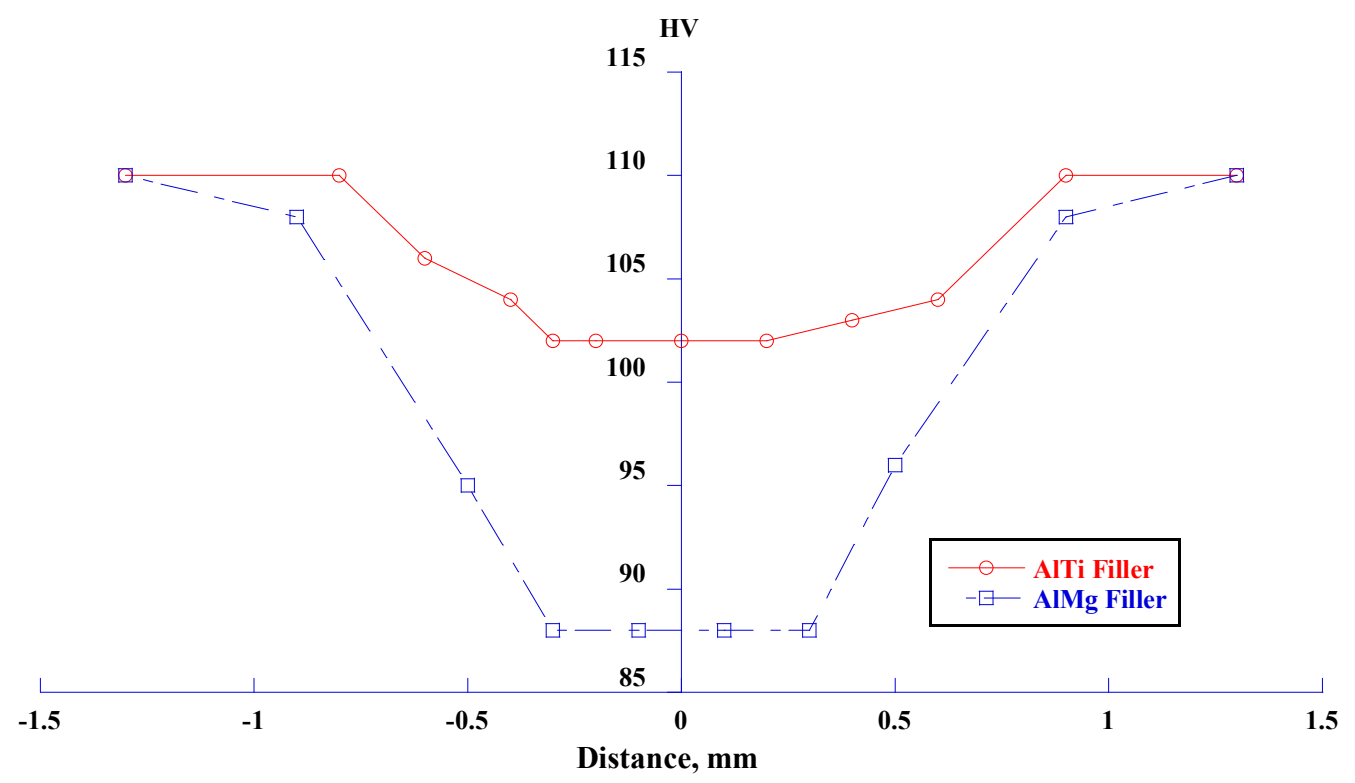

Figure 9. Micro hardness of the cross section of the weld joint of AA7020.

\section{Conclusions}

- In order to obtain an efficient laser welding process, the effects of process parameters such as peak power and welding speed on the width and penetration must be taken into consideration. The welding speed and laser peak power were optimized at $1 \mathrm{~mm} / \mathrm{s}$ and at $0.91 \mathrm{~kW}$ respectively. These values give the highest aspect ratio. Therefore, from the quality point of view, these values give the best result.

- Ramp-down pulse shaping when compared to the square pulse shaping gives a spot weld that is free from visible cracks and porosity.

- Fine grains having an average size of $2.00 \pm 0.26 \mu \mathrm{m}$ were achieved with the joints welded with Al-5Ti-B filler metal, and the yield strength of the welded joint was $97 \%$ of the base metal yield strength. The joints with Al-5Mg have columnar grains and also show some porosity in the weld 
zone. The yield strength was lower than that of the joints using Al-5Ti-B at $67 \%$ of the base metal yield strength.

Author Contributions: S.B.A. designed and performed the experiment and wrote the manuscript; I.L. supervised the experiment and reviewed the manuscript; A.K. helped with sample preparation; A.S. supervised the experiment, reviewed the manuscript, and helped with discussion of the results.

Conflicts of Interest: The authors declare no conflict of interest.

\section{References}

1. Casalino, G.; Mortello, M.; Peyre, P. FEM Analysis of Fiber Laser Welding of Titanium and Aluminum. Procedia CIRP 2016, 41, 992-997. [CrossRef]

2. Dilthey, U.; Keller, H.; Ghandehari, A. Laser beam welding with filler metal. Steel Res. 1999, 70, 198-202. [CrossRef]

3. Zhang, C.; Gao, M.; Zeng, X. Effect of microstructural characteristics on high cycle fatigue properties of laser-arc hybrid welded AA6082 aluminum alloy. J. Mater. Process. Technol. 2016, 231, 479-487. [CrossRef]

4. De Siqueira, R.H.M.; de Oliveira, A.C.; Riva, R.; Abdalla, A.J.; Baptista, C.A.R.P.; de Lima, M.S.F. Mechanical and microstructural characterization of laser-welded joints of 6013-T4 aluminum alloy. J. Braz. Soc. Mech. Sci. Eng. 2014, 37, 133-140. [CrossRef]

5. Pinto, L.A.; Quintino, L.; Miranda, R. Laser welding of dissimilar aluminium alloys with filler material. Weld. World 2010, 54, 333-341.

6. Enz, J.; Riekehr, S.; Ventzke, V.; Huber, N.; Kashaev, N. Fibre laser welding of high-alloyed Al-Zn-Mg-Cu alloys. J. Mater. Process. Technol. 2016, 237, 155-162. [CrossRef]

7. Wang, W.; Yang, X.; Li, H.; Cong, F.; Liu, Y. Effect of laser welding parameters on formation of NiTi shape memory alloy welds. Adv. Mater. Sci. Eng. 2014, 2014, 494851. [CrossRef]

8. Gandra, J.; Pereira, D.; Miranda, R.M.; Vilaça, P. Influence of process parameters in the friction surfacing of AA 6082-T6 over AA 2024-T3. Procedia CIRP 2013, 7, 341-346. [CrossRef]

9. Alshaer, A.W.; Li, L.; Mistry, A. Effect of filler wire properties on porosity formation in laser welding of AC-170PX aluminium alloy for lightweight automotive component manufacture. Proc. Inst. Mech. Eng. Part B J. Eng. Manuf. 2017, 231, 994-1006. [CrossRef]

10. Kashani, H.T.; Kah, P.; Martikainen, J. Laser Overlap Welding of Zinc-coated Steel on Aluminum Alloy. Phys. Procedia 2015, 78, 265-271. [CrossRef]

11. Hajavifard, R.; Motahari, M.; Özden, H.; Miyanaji, H.; Kafashi, S. The Effects of Pulse Shaping Variation in Laser Spot-Welding of Aluminum. Procedia Manuf. 2016, 5, 232-247. [CrossRef]

12. Kah, P.; Martikainen, J. Current trends in welding processes and materials: Improve in effectiveness. Rev. Adv. Mater. Sci. 2012, 30, 189-200.

13. Ukar, E.; Lamikiz, A.; Martinez, S.; Tabernero, I.; López de Lacalle, L.N. Roughness Prediction on laser polish surfaces. J. Mater. Process. Technol. 2012, 212, 1305-1313. [CrossRef]

14. Calleja, A.; Tabernero, I.; Ealo, J.A.; Campa, F.J.; Lamikiz, A.; López de Lacalle, L.N. Feed rate calculation algorithm for the homogeneous material deposition of blisk blades by 5 -axis laser cladding. Int. J. Adv. Manuf. Technol. 2014, 74, 1219-1228. [CrossRef]

15. Calleja, A.; Tabernero, I.; Fernández, A.; Celaya, A.; Lamikiz, A.; López de Lacalle, L.N. Improvement of strategies and parameters for multi-axis laser cladding operations. Opt. Lasers Eng. 2014, 56, 113-120. [CrossRef]

16. Von Witzendorff, P.; Kaierle, S.; Suttmann, O.; Overmeyer, L. Using pulse shaping to control temporal strain development and solidification cracking in pulsed laser welding of 6082 aluminum alloys. J. Mater. Process. Technol. 2015, 225, 162-169. [CrossRef]

17. Rao, G.S.; Rao, V.V.S.; Rao, S.R.K. Microstructure and Mechanical Properties of Welded Joints of Aluminum Alloy AA7020-T6 Obtained by Friction Stir Welding. Met. Sci. Heat Treat. 2017, 59, 139-144.

18. Cao, L.; Yang, Y.; Jiang, P.; Zhou, Q.; Mi, G.; Gao, Z.; Rong, Y.; Wang, C. Optimization of Process Parameters of AISl 316L laser welding influenced by external magnetic field combining RBFNN and GA. Results Phys. 2017, 7, 1329-1338. 
19. Loginova, I.; Khalil, A.; Pozdniakov, A.; Solonin, A. Zolotorevskiy, V. Effect of pulse laser welding parameters and filler metal on microstructure and mechanical properties of Al-4.7Mg-0.32Mn-0.21Sc-0.1Zr alloy. Metals 2017, 7, 564. [CrossRef]

20. Wu, S.C. Porosity, Element Loss, and Strength Model on Softening Behavior of Hybrid Laser Arc Welded Al-Zn-Mg-Cu Alloy with Synchrotron Radiation Analysis. Weld. J. 2013, 3, 64-91.

21. Wu, S.C.; Yu, C.; Yu, P.S.; Buffière, J.Y.; Helfen, L.; Fu, Y.N. Corner fatigue cracking behavior of hybrid laser AA7020 welds by synchrotron X-ray computed microtomography. Mater. Sci. Eng. A 2016, 651, $604-614$. [CrossRef]

(c) (C) 2018 by the authors. Licensee MDPI, Basel, Switzerland. This article is an open access article distributed under the terms and conditions of the Creative Commons Attribution (CC BY) license (http://creativecommons.org/licenses/by/4.0/). 